\title{
Perverse Effects of Other-Referenced Performance Goals in an Information Exchange Context
}

\author{
P. Marijn Poortvliet $\cdot$ Frederik Anseel · \\ Onne Janssen • Nico W. Van Yperen • \\ Evert Van de Vliert
}

Received: 8 February 2011/ Accepted: 23 June 2011/Published online: 23 August 2011

(c) The Author(s) 2011. This article is published with open access at Springerlink.com

\begin{abstract}
We argue and demonstrate that an emphasis on outperforming others may lead to perverse effects. Four studies show that assigning other-referenced performance goals, relative to self-referenced mastery goals, may lead to more interpersonally harmful behavior in an information exchange context. Results of Study 1 indicate that assigned performance goals lead to stronger thwarting behavior and less accurate information giving to an exchange partner than assigned mastery goals. Similarly, in Study 2 performance goal individuals more subtly deceived highly competent opponents relative to lowly competent opponents, who received more blatant treatment. Finally, Studies 3 and 4 show in methodologically complementary ways that tactical deception considerations may account for the interpersonally harmful behavior of performance goal individuals.
\end{abstract}

Keywords Achievement goals - Interpersonally harmful behavior - Information exchange $\cdot$ Tactical deception

P. M. Poortvliet ( $₫)$

Communication Science Group, Wageningen University,

P.O. Box 8130, 6700 EW Wageningen, The Netherlands

e-mail: marijn.poortvliet@wur.nl

F. Anseel

Department of Personnel Management

and Work and Organizational Psychology,

Ghent University, Ghent, Belgium

O. Janssen

Department of Human Resource Management and Organizational Behavior, University of Groningen, Groningen, The Netherlands

N. W. Van Yperen · E. Van de Vliert

Department of Social and Organizational Psychology,

University of Groningen, Groningen, The Netherlands
The other thing I found is that a lot of people will not tell you their protocol exactly the way they did it ... Even if you talk to them on the phone and they will tell you-but they left out something, and that's critical ... So you can never repeat it.

(Anderson et al. 2007, p. 451)

Scholarly gossip is filled with legends of rivalry (Kennedy 1997). As reflected in the quote above, stories abound about research labs at top research institutions where principal investigators hire several junior researchers for a short period of time with the clear message that only the one who obtains the best research results will be hired on a more permanent basis. Imposing such performance goals on individuals can trigger individuals to engage in forms of harming others. A recent publication in Nature reports a case in which a researcher was sentenced for deliberately and systematically sabotaging the lab work of a colleague in order to get ahead (Maher 2010). Indeed, as suggested by Anderson et al. (2007) the emphasis on outperforming others may lead to perverse effects among scientists, such as strategic game-playing, withholding crucial information, sabotage of other's ability to use one's work, and questionable research conduct. The present series of studies addresses this assumption by testing the hypothesis that the type of goals we set for individuals in achievement situations may lead to interpersonally harmful behavior.

We first frame this issue within the theoretical framework of the achievement goal approach (e.g., Elliot 2005) and highlight the need to extend the current focus of achievement goal research on individual outcomes to potentially negative effects on interpersonal behavior. Subsequently, we develop hypotheses about the likely impact of the two most studied achievement goals, the 
approach versions of performance goals and mastery goals, ${ }^{1}$ on interpersonally harmful behavior. Specifically, we argue that assigning performance goals will lead to more interpersonally harmful behavior than assigning mastery goals. In a first study, we test this main hypothesis by examining two behaviors that are expected to be susceptible to undesirable performance goal effects, namely deceptive information exchange and thwarting behavior, in a simulated achievement situation wherein individuals had the opportunity to interact with each other. In a second study, we test the hypothesis that the perceived task-related competence of interaction partners qualifies the negative interpersonal effects of assigned performance goals with individuals exhibiting more subtle deceptive behavior toward interaction partners with high task-related competence. Finally, in two complementary studies using the same research paradigm, we take a first step toward elucidating the mechanism underlying the observed tactical deceptive behavior of performance goal individuals.

\section{Toward a Social Understanding of Achievement Goals}

Achievement goals reflect the purpose of an individual's achievement pursuits in a particular situation (Harackiewicz and Sansone 1991). Although there are various valuable theories that explain aspects of achievement motivation such as goal setting theory (Locke and Latham 1990) and self-determination theory (Deci and Ryan 1985), one theoretical framework that has become particularly dominant in the last two decades is the achievement goal approach. Within this approach, it is generally agreed upon that achievement goals can be distinguished on the basis of how people define competence (e.g., Elliot 2005). Performance goals ${ }^{2}$ focus on interpersonal standards of

\footnotetext{
${ }^{1}$ Performance goals and mastery goals have typically been portrayed, both implicitly and explicitly, as approach forms of regulation, that is, as goals directed toward positive or desirable events (Elliot 2005). Accordingly, performance-approach goals reflect the desire to do better than others, whereas mastery-approach goals reflect the desire to do better than one has done before (Elliot and McGregor 2001). Because we focus on approach goals in the present research, for the remainder of this article we restrict the use of the terms performance goal and mastery goal to the approach versions of these goals.

${ }^{2}$ Unlike other theoretical conceptualizations, within the achievement goal approach performance goals refer to the aim of having a better performance than others, while mastery goals refer to trying to improve one's own performance. In contrast, in goal setting theory (Locke and Latham 2002), for instance, the term performance goal refers to the performance one attains on a given task-without taking into account others' performance levels. Furthermore, it is possible that an individual tries to strive for superior task mastery relative to others. However, it should be noted that in this paper we exclusively use the terms performance goals as purely other-referenced goals, while mastery goals are conceptualized as purely self-referenced goals.
}

competence, whereas mastery goals focus on intrapersonal competence standards (Dweck 1986; Nicholls 1984; see also Yeo et al. 2009). That is, people who pursue performance goals tend to compare their performances with those of others in order to monitor their progress toward the desired outcome, namely outperforming others, thereby developing an other-referenced focus. In contrast, individuals who strive for mastery goals compare their present performance predominantly with their previous performance, and consequently, they develop a self-referenced focus on outcomes in achievement situations.

Since the early days of achievement goal research, scholars have examined which achievement goals seem most beneficial in different contexts, and should, therefore, be promoted in corresponding achievement situations (e.g., Darnon et al. 2009; Midgley et al. 2001; Payne et al. 2007). While this query has produced valuable insights in the field of human motivation and behavior, the question which of both goals is most constructive in achievement contexts appears difficult to answer. Of course, the answer to this question depends on the outcome variable under study.

Traditionally, the vast majority of achievement goal studies have focused on individual performance as an outcome. Several studies found performance goals to be more strongly associated with better individual performance than mastery goals, whereas the latter tend to have a stronger relationship with intrinsic motivation (e.g., Harackiewicz et al. 2002; Skaalvik 1997). In recent years, a somewhat more complicated picture concerning individual performance effects of achievement goals has emerged. For instance, a meta-analysis (Payne et al. 2007) found performance goals to be unrelated to individual performance measures, whereas mastery goals were generally positively related to these outcomes. These mixed findings seem to suggest that boundary conditions such as type of performance and domain of achievement moderate the effects of achievement goals.

Within the achievement goal approach, one important outcome domain that has received less research attention to date is interpersonal behavior (Poortvliet and Darnon 2010). Achievement goals are often pursued in social situations (e.g., research teams, student groups, and sport teams). If we want to obtain a more complete understanding of the effects of achievement goals, potentially positive and negative interpersonal effects of achievement goals should also be taken into account. Although performance goals may have positive effects on individual performance, reports of undesirable social consequences of assigning performance goals would caution researchers from unequivocally promoting performance goals in achievement situations. Examining the pattern of potentially malicious interpersonal behaviors stemming from performance goals is also important from a theoretical 
perspective. It is possible that some highly characteristic patterns of cognition and action resulting from performance goals pursued in interpersonal achievement situations might have remained undetected resulting from the dominant focus on individual outcomes of previous research.

To date, few studies have focused on interpersonal behavior in achievement goal research. In their work on leader-member exchange, Janssen and Van Yperen (2004) showed that performance goals, but not mastery goals, were negatively related to the perceived quality of the exchange relationship between supervisors and employees. Research by Poortvliet et al. showed that performance goals, relative to mastery goals, lead to a reduced willingness to share valuable information with exchange partners (Poortvliet et al. 2007, 2009b). Also, relative to performance goals, mastery goals were related stronger to backing up behavior, the provision of resources and effort to help team members who are apparently failing to perform well (Porter 2005). Likewise, in the educational domain research suggests that performance goals, relative to mastery goals, are less constructive or even destructive for social relationships. Darnon et al. found that when students have different task-related solutions, performance goals predict relational conflict regulation, that is, by insisting that one is right and the other party is wrong. On the other hand, mastery goals predict epistemic regulation, which means that one tries to find out whether both points of view can be integrated into a joint solution (Darnon et al. 2006). A different line of research in the educational domain consistently shows that mastery goals lead to decreased levels of academic cheating, whereas performance goals are related to increases in academic dishonesty (for a review see Murdock and Anderman 2006).

Thus, trying to outperform others (i.e., pursuing performance goals) versus trying to improve one's own previous performance (i.e., pursuing mastery goals) may importantly affect how people behave in social situations. Indeed, previous studies indicate that performance goals are working less constructive in social situations than mastery goals (e.g., Darnon et al. 2006). The current study goes one step further by showing that performance goals, relative to mastery goals, may not only lead to behavior that is less constructive, but may actually instigate behavior that is targeted at harming the performance of others in the same achievement situation. Also, the present investigation extends previous research by uncovering processes that may explain how performance goals lead to destructive interpersonal outcomes. While policy makers might be encouraged to promote performance goals stemming from the belief that this will lead to superior task performance (as illustrated in the opening example), these goals could lead to unintended paradoxical effects because performance goals may simultaneously strongly prompt negative interpersonal dynamics (cf. Chen 2003).

\section{The Present Research}

The way achievement goals affect how individuals react to others around them may be most notable when they are engaged in task-related information exchange. Such situations offer the opportunity to outperform others or to cooperate and learn from others. Because exchange partners are social comparison targets as well as potential sources of valuable information (Darnon et al. 2007), people with performance versus mastery goals may be expected to differently define, experience, and respond to achievement situations in which information exchange with others takes place (Dweck 1986; Poortvliet et al. 2007).

More specifically, it may be assumed that performance goal individuals will experience negative interdependence, whereas mastery goal individuals will experience positive interdependence in an information exchange context (Deutsch 1949; Johnson and Johnson 1989; Poortvliet et al. 2009a). To be more specific, performance goal individuals may perceive negative outcome interdependence, because they only reach their goal when they outperform others. Furthermore, if information exchange is a means toward goal attainment in social achievement situations, performance goal individuals are likely to perceive this exchange of information as negative means interdependence. This negative outcome and means interdependence makes performance goal individuals vulnerable because their goal attainment is directly and negatively related to the exchange partners' goal attainment. It may be assumed that this vulnerability is threatening to individuals with performance goals because others taking advantage of the shared information will almost automatically obstruct them in attaining their goal of outperforming these others. To protect oneself against this threat, people with performance goals apparently want to prevent exchange partners from profiting from their information exchange. Indeed, earlier research has demonstrated that negative outcome interdependence may result in withholding information to exchange partners (Toma and Butera 2009). Performance goal individuals can, therefore, be expected to engage in deceptive information exchange and thwarting behavior in order to frustrate exchange partners in their goal-directed task endeavors.

In the current conceptualization of achievement goals, mastery goals, in contrast to performance goals, are at heart exclusively intrapersonal in nature because reaching these goals is solely dependent on whether actors manage to improve themselves. Thus, outcomes of individuals with mastery goals are not dependent on others' outcomes, so they are less likely to perceive positive outcome interdependence. 
Rather, mastery goal individuals may perceive positive means interdependence with the other party. That is, information exchange can serve as an important means by which they can reach their individual goal of self-improvement. When people pursue mastery goals, they may, therefore, perceive others around them as helps that may aid them to bolster their performance through cooperation (Poortvliet et al. 2007). Perceptions of positive means interdependence associated with mastery goals can be expected to activate concrete action plan goals that instigate mastery goal individuals to team up with others (cf. DeShon and Gillespie 2005). This may enhance mastery goal individuals' willingness to exchange high-quality information with potential exchange partners in order to obtain useful task-related information in return, which can advance the attainment of their goal of competence development.

\section{Study 1}

In Study 1, participants were asked to give task-related information to another participant and to set the level of an unpleasant noise that the other allegedly would hear while engaged in task performance. In this way, we were able to test the idea that, in a social exchange situation, individuals with performance goals would behave in a more interpersonally harmful way than mastery goal individuals. Specifically, in this first study we assessed two measures of harmful behavior, the accuracy of information given to the exchange partner and behavior that could thwart exchange partners' goal-directed task endeavors.

\section{Method}

\section{Participants and Design}

Forty-one students (30 women and $11 \mathrm{men}^{3}$ ) with an average age of 20.46 years participated in the study and were paid (6 Euros) or received partial course credit for their participation. Participants were randomly assigned to one of the two achievement goal conditions (performance goal vs. mastery goal).

\section{Procedure}

Upon arrival at the laboratory, each participant was led to a separate cubicle containing a computer with a monitor and a keyboard. Next to the monitor, participants found pieces of

\footnotetext{
${ }_{3}$ In the studies presented in this paper, gender was proportionally distributed among conditions. Gender had no main or interaction effects on the dependent variables in the studies and was thus dropped from the analyses.
}

paper and a pencil. Participants were told that the computer was connected to the computer network and that it was possible to communicate with others. The computers were used to present the stimulus information and to collect data.

The study started off by presenting an adapted version of the winter survival exercise (WSE; Johnson and Johnson 2009) to the participants. This exercise consisted of reading a scenario that described a crash landing of a plane in a very cold and desolate area. Both pilots were killed in the crash and the plane was lost; however, the surviving passengers managed to salvage twelve items from the plane (e.g., a hand axe, a compass, and a lighter). After reading this scenario, the participants were instructed to think about and write down on a form the possible advantages and disadvantages of each of the twelve items. Then, the participants ranked the twelve items in order of their importance for survival on a piece of paper and entered this ranking into the computer.

The interpersonal nature of the exercise was introduced by informing the participants that another participant had also carried out this assignment, and that information about the WSE would be exchanged with this other person. That is, the participants were told that they would give information to the other and that subsequently they would receive task-related information from the other in return. After that, the participants were told that they would make a second, definitive ranking of the twelve items. After presenting this overview of the study, the goal manipulation was induced. In line with earlier work (e.g., Darnon et al. 2010; Van Yperen 2003), the following goals were assigned: "Perform better on your second ranking compared to the other's ranking" (performance goal), or "perform better on your second ranking compared to your first ranking" (mastery goal). Next, the participants elaborated on their assigned goal in order to intensify the achievement goal manipulation. Participants were asked to write down their answers to two questions about their thoughts and feelings evoked by the specific goal that was assigned to them (cf. Poortvliet et al. 2007).

The participants were then asked to send a ranking to the other by means of the computer network. The participants had the freedom to choose whether they sent the actual ranking they had drawn up earlier or a different ranking to the other person. After the participants had given a ranking to the other, instructions were given that the purpose of the study was to investigate the effect of noise pressure on performance. Furthermore, it was communicated that due to a network malfunction the other participant would receive their original ranking that they had entered into the computer, and not the ranking that they just had selected for the other. Then, it was explained that the other participant would process this information under noise pressure. The participants were informed that they had to set the level of 
noise that the other participant would hear while making the definitive ranking on the WSE. This could be done by adjusting the level of noise the other would allegedly hear, which ranged from 1 (very quiet) to 16 (very loud). This procedure parallels to some degree the paradigm of Bushman and Baumeister (1998) in which the level of noise reflected aggressive behavior. However, the present measure did not assess hostile aggression, but rather an instrumental behavior directed specifically at thwarting the other's task-related performance (cf. Berkowitz 1998). While putting the noise at the desired level, the participants heard this noise themselves via the computer speakers. By default, the noise was set on level 8 , and the participants had the opportunity to vary the noise level until they set the definitive noise level. After this, the manipulation check was assessed, the participants were thanked for their participation and they were thoroughly debriefed. Note that the participants did not receive information from the other participant, and they did not make a final ranking. After measuring the noise level, the experiment actually ended.

\section{Measures}

Manipulation check The participants were asked to indicate which specific goal had been assigned to them for making the exercise. Participants could choose between a performance goal and a mastery goal.

Information accuracy was assessed by computing the Spearman rank order correlation between the initial ranking the participants actually produced and the ranking they gave to the other. This measure enabled us to detect modifications between the initial ranking the participants made and the ranking that they made available to the other, and thus indicated the extent to which participants were accurate in providing information about their first task performance (Poortvliet et al. 2007). A correlation of 1 indicated that there was no difference between the initial ranking and the ranking that the participants gave to the other. The lower the correlation, the more modifications participants made to the ranking they gave to the other compared to their initial ranking. Because correlations typically are not normally distributed, the Spearman rank order correlation was standardized by means of the Fisher $r$-to- $z$ transformation.

Thwarting behavior The participants were asked to adjust the level of a noise that the other participant allegedly would hear during the subsequent task performance. This noise could be set on 16 different levels, ${ }^{4}$ ranging from 1 (very quiet) to 16 (very loud).

\footnotetext{
${ }^{4}$ Each possible higher level corresponded with an increase in magnitude of $2 \mathrm{~dB}$. The decibel scale is logarithmic; an increase of $3 \mathrm{~dB}$ equals a doubling of the sound intensity.
}

Results

\section{Manipulation Check}

A chi-square test, comparing the observed frequencies of cases with the expected frequencies, revealed that the goal manipulation was successful, $\chi^{2}(1, N=41)=33.69$, $p<0.001$. The achievement goal that was assigned to them was correctly recalled by $95.1 \%$ of the participants. ${ }^{5}$

\section{Information Accuracy}

An analysis of variance (ANOVA) showed an effect of goal manipulation on the information accuracy measure, ${ }^{6}$ $F(1,39)=5.68, p=0.02, \eta_{\mathrm{p}}^{2}=0.13$. In line with our expectations, in the performance goal condition participants gave less accurate information to the other participant $\left(M_{r}=0.83 ; M_{z}=4.23, S D_{z}=2.65\right)$ than in the mastery goal condition $\left(M_{r}=0.99 ; M_{z}=5.74, S D_{z}=1.14\right)$.

\section{Thwarting Behavior}

An ANOVA test showed an effect of goal manipulation on the thwarting behavior measure, $F(1,39)=5.69$, $p=0.02, \quad \eta_{\mathrm{p}}{ }^{2}=0.13$. As expected, performance goal participants set a louder noise for the other participant $(M=7.35, S D=5.24)$ than participants with a mastery goal $(M=4.05, S D=3.49)$.

Furthermore, the thwarting behavior measure was negatively correlated with the information accuracy measure, $r=-0.41, p<0.01$, indicating that participants who gave more accurate information set a lower level of noise for the other participant.

\section{Study 2}

The results of Study 1 showed that individuals who were instructed to pursue a performance goal were more willing than mastery goal individuals to display interpersonally harmful behavior. Specifically, they were willing to sabotage the task performance of their exchange partners by giving less accurate information, and by choosing a louder noise level that the other would hear while making a definitive ranking on the task. In fact, as the difference between the performance and the mastery conditions was

\footnotetext{
5 Excluding participants who recalled a different goal than the one that was assigned to them did not meaningfully change the results of Study 1 and Study 2.

${ }^{6}$ We also report the means of unstandardized Spearman correlations, because these means are more straightforward to interpret than the means of Fisher $z$-values. However, all reported tests were performed on the standardized $z$-values.
} 
greater than three sound levels, this means that participants in the performance goal conditions set a level of white noise which was more than four times as loud as the participants in the mastery condition did.

We argued that performance goal individuals tend to perceive negative outcome and means interdependencies with others in interpersonal achievement situations, making them susceptible to engaging in deceptive information exchange and thwarting behavior. Another important implication for performance goal individuals is that goal achievement is crucially dependent on the task-related competence of others. Furthermore, highly competent exchange partners are more difficult to deceive, and giving them blatantly poor information is likely an action too transparent to conduct. It, therefore, makes sense for performance goal individuals to subtly lower the quality of information given when confronted with a highly competent other, while unconcealed poor information can be given to less competent others. This idea is in line with research by Langer (1975, Study 1) who showed that individuals in competition with a "schnook" other wagered more money compared to when they dealt with a "dapper" other.

Thus, when one has to exchange information with others who have different levels of task-related competence, the other-referenced focus of performance goal individuals may lead to different effects compared to the self-referenced focus of mastery goal individuals. To better understand how performance goals, relative to mastery goals, lead to deceptive information exchange, Study 2 considers the moderating role of others' competence. Specifically, we anticipated that individuals with performance goals would give less accurate information than mastery goal individuals. However, performance goal individuals may be more subtle in their deceptive information giving when they deal with a more competent exchange partner, compared to dealing with a less competent exchange partner. That is, when an exchange partner has a low task-related competence, it is easier to provide this person with blatantly poor information, simply because one may expect that the chance of detection is smaller. Conversely, if the exchange party is highly competent, performance goal individuals may choose to "play it safe" and only subtly lower the quality of the exchanged information in order to avoid the highly competent party detecting the deception and thereby not using the misleading information to their disadvantage. Therefore, in Study 2 we tested our expectation that information about the competence of the exchange partner qualifies the effect on the information given by people with performance goals, but not by those with mastery goals. Thus, we expected that, relative to their mastery goal counterparts, performance goal individuals with a lowly competent exchange partner would give more blatantly inaccurate information than performance goal individuals with a highly competent exchange partner.

Method

\section{Participants and Design}

One hundred students (58 women and 42 men) with an average age of 22.60 years participated in the study and were paid ( 7 Euros) or received partial course credit for their participation. They were randomly assigned to one of the conditions of the 2 (achievement goal: performance vs. mastery) $\times 2$ (other's competence: low vs. high) factorial design. The design was balanced with 25 participants taking part in each of the conditions.

\section{Procedure}

The procedure was identical to that of Study 1 except for the below-mentioned points. After making a ranking on the WSE and entering this ranking in the computer, the participants were told that an ideal ranking existed, and that a ranking could be compared with this ideal ranking, yielding a score with a possible range of $1-100$ points. This was followed by the disclosure that another participant had also carried out this assignment and that they would now exchange rankings. It was then told that, in order to have a broad idea about the performance of this other person, the participant would receive information about the quality of the other's ranking. Participants were informed that this ranking was worth either 77 points (high other's competence condition) or 23 points (low other's competence condition). Participants were instructed that they would first give a ranking to the other, after which they would receive a ranking from the other, and then they were expected to make a final ranking of the twelve items. However, the study actually stopped after the participants gave their ranking to the other.

\section{Measures}

Manipulation checks Achievement goal manipulation was checked by asking participants to indicate which specific goal was assigned to them. Manipulation of other's competence was checked by asking the participants to indicate how many points the other received on their ranking (1-100 points). The manipulation of other's competence was further checked by asking participants how high $(1=$ very low, $7=$ very high $)$ and $\operatorname{good}(1=$ very bad, 7 = very good) they thought the number of points the other received was. These judgments were averaged to form a reliable competence judgment scale $(\alpha=0.86)$. 
Information accuracy was assessed in the same way as in Study 1.

Results

\section{Manipulation Checks}

A chi-square test, comparing the observed frequencies of cases with the expected frequencies, revealed that the goal manipulation was successful, $\chi^{2}(1, N=100)=77.44$, $p<0.001$. The achievement goal that was assigned to them was correctly recalled by $94.0 \%$ of the participants.

A $2 \times 2$ ANOVA on the number of points the other received yielded only a main effect of other's competence, $F(1,96)=376.28, p<0.001$. As expected, participants who had received information about the other being highly competent reported that the other received more points $(M=72.92, S D=13.07)$ than those who had received information about the other being lowly competent $(M=26.42, S D=10.86)$. Next, a $2 \times 2$ ANOVA on the competence judgment scale yielded only a main effect of other's competence, $F(1,96)=165.74, p<0.001$. As intended, participants who had received high competence information reported that the other had higher competence $(M=5.33, S D=1.00)$ than those who had received low competence information $(M=2.77, S D=0.98)$.

\section{Information Accuracy}

The means and standard deviations of the dependent variable, information accuracy, are displayed in Table 1. A $2 \times 2$ ANOVA yielded the expected main effect of achievement goal, $F(1,96)=15.30, p<0.001, \eta_{\mathrm{p}}{ }^{2}=$ 0.14 , thereby replicating the finding of Study 1 . No main effect of other's competence was found, $F(1,96)=1.65$, $n s, \eta_{\mathrm{p}}{ }^{2}=0.02$, but the anticipated interaction effect was significant, $F(1,96)=4.74, p=0.03, \eta_{\mathrm{p}}{ }^{2}=0.05$.

In order to test for our hypothesis, we performed an a priori contrast analysis following the recommendations of Abelson and Prentice (1997; see also Rosenthal et al. 2000). A contrast weight of -5 was applied to the performance goal by low other's competence condition, a weight of -1 to the performance goal by high other's competence condition, and the two mastery goal conditions each had a weight of +3 . In line with predictions, this contrast was significant, $t(96)=4.58, p<0.001$. To further interpret this finding, additional contrast testing revealed that the performance goal by low other's competence manipulation produced less accurate information giving to the other than the performance goal by high other's competence manipulation, $t(96)=2.45, p=0.01$ (one-sided). As expected, the contrast that tested the difference between both mastery goal conditions was not significant, $t(96)=0.63$, ns. Two final contrasts showed that the performance goal by high other's competence manipulation produced less accurate information giving than the two mastery goal conditions, $t(96)=1.78, \quad p=0.04$ (one-sided), but the difference between the performance goal by low other's competence condition and the mastery goal conditions was much larger, $t(96)=4.08, p<0.001$ (one-sided).

\section{Study 3}

The results of Study 2 corroborated our expectations and showed that the exchange partner's level of competence influences the information giving behavior for individuals with performance goals, but not for individuals with mastery goals. So, mastery goals lead to accurate information giving irrespective of the competence level of the exchange partner. This finding is in line with earlier research showing that mastery goal individuals adopt an orientation toward reciprocity when engaged in information exchange (Poortvliet et al. 2007). Such an orientation also coincides with making attempts to provide an exchange partner with valuable information, even when one's own competence turns out to be low (Poortvliet et al. 2009b). In accordance with such a cooperative mindset, the current study showed that mastery goal individuals are willing to give accurate information to both lowly and highly competent exchange partners.

In contrast, a low competence level of their exchange partner led people with a performance goal to give less accurate information than people with a performance goal and highly competent exchange partner. In turn, performance goal individuals with a highly competent exchange partner gave less accurate information than mastery goal individuals (either with a lowly or highly competent exchange partner), but in a more subtle manner than performance goal individuals with a lowly competent exchange partner tended to do.

In Study 3, in which a performance goal was imposed on all participants, we set out to investigate why precisely performance goal individuals take into account the competence of others in an exchange situation. When individuals find themselves engaged in an information exchange situation such as this, they are likely to ask themselves the question: "What information sharing strategies may help me reach my goals?" A strategy that may be particularly helpful to performance goal individuals is tactical impression management, that is, a person's will to maintain the positive image that others have of them in order to attain their other-referenced performance goals (Vilanova and Bernardin 1989; see also Jones 1990). Namely, if performance goal individuals want to outperform others, it is important that their exchange partners have confidence and trust in them and subsequently adopt the poor information 
Table 1 Means and standard deviations of information accuracy as a function of achievement goal and level of other's competence (Study 2)

\begin{tabular}{|c|c|c|c|c|c|c|}
\hline \multirow[t]{3}{*}{ Other's competence } & \multicolumn{6}{|l|}{ Goal } \\
\hline & \multicolumn{3}{|c|}{ Performance } & \multicolumn{3}{|c|}{ Mastery } \\
\hline & $M_{r}$ & $M_{z}$ & $S D_{z}$ & $M_{r}$ & $M_{z}$ & $S D_{z}$ \\
\hline Low & 0.68 & 3.11 & 2.79 & 0.99 & 5.75 & 1.23 \\
\hline High & 0.82 & 4.61 & 2.51 & 0.96 & 5.36 & 1.77 \\
\hline
\end{tabular}

Note: $M_{r}$ mean Spearman's correlation, $M_{z}$ mean Fisher's $z$ value, $S D_{z}$ standard deviation of Fisher's $z$-value. Higher values indicate giving of more accurate information

that is provided. So, tactical impression management may be the appropriate strategy to subtly convince their interaction partners that the information they receive is indeed accurate and helpful. Thus, performance goal individuals may prevent detection of their own performance goal ("outperforming others") by subtly masking their deceptive behavior (Wathne and Heide 2000; Wong et al. 2005). Hence, the competence of exchange partners may guide the tactical deception considerations made by performance goal individuals to cover their deceptive behavior.

However, measurement of such a process variable may actually interfere with a sound measurement of the outcome variable (Spencer et al. 2005). Given that it may not be very socially desirable to hold tactical deception considerations, measurement of such a process may actually prevent the outcome variable, information accuracy, to occur altogether, or to unintentionally prime the process in all participants. Because in this investigation our main goal was to uncover the psychological process underlying the information giving behavior of performance driven individuals, we followed the experimental-causal-chain approach to mediation (Sigall and Mills 1998; Spencer et al. 2005). Specifically, in Study 3 we aimed to demonstrate that the level of an exchange partner's competence affects the considerations about tactical deceptions made by performance goal individuals. Then, in Study 4 we manipulated tactical deception considerations in order to demonstrate that those considerations determine the accuracy of the information provided by performance goal individuals to exchange partners in interpersonal achievement situations.

\section{Method}

\section{Participants and Design}

Fifty-nine students (37 women and 22 men) with an average age of 20.09 years participated in the study and were paid (7 Euros) or received partial course credit for their participation. Participants were randomly assigned to one of the two competence conditions (other's competence low vs. high).

\section{Procedure}

The procedure was identical to that of Study 2, except for the below-mentioned points. After the participants completed their individual ranking on the WSE, they were informed that an optimal ranking existed and that they had scored between 75 and 80 points out of 100 possible points. Thus, although in Study 2 it may be assumed that participants did their best on their first task performance and felt that the task-related information they possessed was valuable, in Study 3 the participants were now provided with clear and unambiguous feedback that they themselves possessed high-quality task-related information. Furthermore, they were informed that another participant had also executed the survival exercise and that the other's ranking was worth either between 75 and 80 points (high other's competence condition) or between 20 and 25 points (low other's competence condition). Next, all participants were assigned a performance goal. After the participants' tactical deception considerations were assessed, the study ended and the participants were thanked for their participation and debriefed.

\section{Measures}

Manipulation check Manipulation of other's competence was checked by asking the participants to indicate how many points the other received on their ranking and by asking participants how high and good they thought the number of points the other received was. These judgments were averaged to form a reliable competence judgment scale $(\alpha=0.98)$.

Tactical deception considerations were assessed with five items $(\alpha=0.69)$. We were not aware of an existing instrument that covers our operationalization of tactical deception considerations in the present task context, and, therefore, we developed the current scale: "I hope the other finds me trustworthy", "I want to appear competent to the other", "I want to prevent that the other finds me clueless", "I find it important that the other has confidence in my ranking" $(1=$ strongly disagree, $7=$ strongly agree $)$, and 
"The other wouldn't notice it anyway if I would give poor information" ( 1 = strongly disagree, 7 = strongly agree; reverse scored). So, higher ratings on this scale mean that participants made more considerations directed at presenting themselves as a trustworthy and competent exchange partner, and at covering their deceptive behavior.

Results

\section{Manipulation Check}

An ANOVA on the number of points the other received yielded an effect of other's competence, $F(1,57)=694.76$, $p<0.001$. As expected, participants who had received high competence information about the other reported that the other received more points $(M=76.43, S D=2.16)$ than those who had received low competence information $(M=26.86, S D=10.07)$. Next, an ANOVA on the competence judgment scale yielded an effect of other's competence, $F(1,57)=406.21, p<0.001$. As intended, participants who had received information about the other being highly competent reported that the other had higher competence $(M=5.78, S D=0.36)$ than those who had received information about the other being lowly competent $(M=2.45, S D=0.83)$.

\section{Tactical Deception Considerations}

An ANOVA showed a significant effect of the other's competence manipulation on the tactical deception considerations measure, $F(1,57)=4.45, p=0.04, \eta_{\mathrm{p}}{ }^{2}=0.07$. As expected, when the other's competence was high, performance goal participants reported more tactical deception considerations $(M=4.86, S D=0.89)$ than when the other's competence was low $(M=4.32, S D=1.08)$.

\section{Study 4}

Study 3 satisfied the first requirement for documenting mediation via the experimental-causal-chain approach. Because measuring the process (tactical deception considerations) could bias the dependent variable (information accuracy), in Study 3 we only measured the proposed process variable. Recent studies have demonstrated how the mere measurement of process variables, may strengthen their weight in the dependent variable (e.g., Kahneman et al. 2006). In Study 4, we experimentally manipulated tactical deception considerations in order to investigate whether stronger tactical deception considerations are associated with giving relatively more accurate information by performance goal individuals, and thereby we tested the second requirement for documenting mediation.
Method

\section{Participants and Design}

Seventy students (59 women and 11 men) with an average age of 19.51 years participated voluntarily in exchange for partial course credit. Participants were randomly assigned to one of the two tactical deception considerations conditions (weak vs. strong tactical deception considerations). The design was balanced with 35 participants taking part in each of the conditions.

\section{Procedure}

The procedure was identical to that of Study 3, except for the below-mentioned points. After the participants had completed their individual ranking on the WSE, they were informed that an optimal ranking existed and that they had scored between 75 and 80 points out of 100 possible points. Thus, the participants were provided with clear feedback that they themselves possessed high-quality task-related information. Participants were then informed that another participant had also executed the survival exercise, but they did not receive information about the other's competence. Next a performance goal was assigned. Finally, we manipulated tactical deception considerations. Participants in the weak tactical deception considerations condition read the following instruction:

In order to perform better on your second ranking as compared to the other's ranking, it is not important that the other finds you trustworthy. Also, the other doesn't need to have confidence in your ranking. After all, the other wouldn't notice it anyway if you would give poor information.

Participants in the strong tactical deception considerations condition received the following instruction:

In order to perform better on your second ranking as compared to the other's ranking, it is very important that the other finds you trustworthy. Also, it's important that the other has confidence in your ranking. After all, the other would notice it if you would give poor information.

The information giving behavior was then measured and the manipulation check was assessed, before thanking and debriefing the participants.

\section{Measures}

Manipulation check Tactical deception considerations manipulation was checked by assessing the same tactical deception considerations measure as in Study $3(\alpha=0.76)$. 
Information accuracy was assessed in the same way as in Study 1 and Study 2.

Results

\section{Manipulation Check}

An ANOVA on the tactical deception considerations measure yielded the anticipated effect of tactical deception considerations manipulation, $F(1,68)=10.60, p<0.001$. As expected, participants in the weak tactical deception considerations condition reported weaker tactical deception considerations $(M=4.01, S D=1.13)$ than participants in the strong tactical deception considerations condition $(M=4.80, S D=0.87)$.

\section{Information Accuracy}

An ANOVA with information accuracy as the dependent variable also yielded a main effect of the tactical deception considerations manipulation, $F(1,68)=6.57, p=0.01$, $\eta_{\mathrm{p}}{ }^{2}=0.09$. As expected, in the weak tactical deception considerations condition participants gave less accurate information to the other participant $\left(M_{r}=0.24 ; M_{z}=1.35\right.$, $\left.S D_{z}=2.72\right)$ than in the strong tactical deception considerations condition $\left(M_{r}=0.79 ; M_{z}=2.95, S D_{z}=2.53\right)$.

\section{General Discussion}

In these four studies, the results indicate that in a social achievement situation the pursuit of performance goals has interpersonally detrimental effects. These undesirable consequences of performance goals go further than a simple reluctance to engage in sharing valuable information with others. Specifically, it was shown that in an information exchange context, performance goal individuals actively gave less accurate information to their exchange partners while at the same time they were more willing to actively thwart the task performance of their exchange partners by means of blasting white noise, relative to mastery goal individuals. Also, as the results demonstrated, assigning performance goals made individuals give less accurate information to lowly competent others than to highly competent others, an effect that did not emerge when mastery goals were assigned.

Furthermore, the last two studies showed that pursuing performance goals tends to lead to tactical deception of exchange partners. Performance goal individuals aim to keep their deceptive behavior under the radar when confronted with highly competent others, so that the low quality of the information that they provided will remain undetected and hopefully will be adopted by their highly competent exchange partners, which will consequently undermine the others' performance. The mediating role of tactical deception considerations was identified by means of an experimental-causal-chain design. One of the drawbacks of this type of design is that we cannot determine how much of the information accuracy effect is explained by these tactical deception considerations. However, the main purpose of the current research was to establish causality rather than determining the exact amount of explained variance (for a discussion on this issue, see Spencer et al. 2005). Moreover, assessing tactical deception considerations could have distorted accurate measurement of the information accuracy measure, when both variables would have been assessed in one design.

\section{Theoretical and Practical Implications}

There is an ongoing debate concerning the link between mastery goals and performance goals, on the one hand, and outcome variables, on the other. In general, mastery goals are associated with positively valenced outcome variables, including self-efficacy, positive affectivity, intrinsic motivation, well-being, and actual performance (e.g., Elliot 2005; Kaplan and Maehr 1999; Van Yperen 2006). In contrast, performance goals are typically associated with both positively and negatively valenced variables. For example, the focus on doing well relative to others may keep performance efforts channeled toward the normative standards that eventuate in high levels of performance (Elliot and Church 1997; Harackiewicz et al. 1997). However, at the same time, performance-approach goals may involve costs in terms of interest (Harackiewicz et al. 2002), anxiety, worry, negative affect (Elliot and McGregor 2001; Van Yperen 2006), dissatisfaction (Van de Vliert and Janssen 2002; Van Yperen and Janssen 2002), and (academic) cheating (Anderman and Midgley, 2004; Van Yperen et al., 2011). In addition, recent interpersonal achievement goal research suggests that, relative to mastery goals, performance goals may be less constructive in social situations (e.g., Darnon et al. 2006; Poortvliet and Darnon 2010; Porter 2005). The present investigation extends these earlier research endeavors by showing that, relative to mastery goals, performance goals may instigate interpersonally harmful behaviors toward others by activating tactical considerations. Thus, assigning performance goals may be detrimental to the quality of social exchange relationships, and, as a consequence, may have the potential to negatively affect the performances of others.

This idea relates to work in the negotiation domain by Kray and Haselhuhn (2007). They showed that individuals who see negotiation skills as malleable (i.e., incremental 
theorists) were more likely to set mastery goals for themselves than individuals who see negotiation skills as fixed (so-called entity theorists). More importantly, incremental theorists were able to outperform the entity theorists when it came to actual negotiating. Just like in negotiations, information exchange situations are characterized by a tension between creating and claiming value (cf. Lax and Sebenius 1986). In this manner, sharing and combining unique ideas has the potential to increase the size of the pie from which exchange partners can profit. Because mastery goal individuals act in social exchange situations in a more benevolent manner, they will presumably create a lot of information and the high-quality exchange relationships they tend to establish will likely ensure that, unlike their performance goal counterparts, mastery goal individuals may effectively profit from their exchanges with others.

The fact that performance goal individuals are willing to deceive others in order to establish superiority may be considered conflict behavior, because it represents acts aimed at obstructing the task efforts of the other party (Van de Vliert 1997). In that vein, the present study also contributes to the conflict literature because the results show that instigating achievement goals has important consequences for the potential emergence of subsequent conflict behavior in an information exchange context (cf. Einarsen et al. 2009). In the conflict tradition, a myriad of conflict antecedents have been investigated, but little is known about the individual micro-determinants of conflicts (Van de Vliert 1998). Although earlier research indicated that poor goal setting and faulty organizational goals might lead to unethical behavior (Schweitzer et al. 2004; Vardi and Weitz 2004), the current investigation demonstrates that potential conflict behavior may arise from the specific achievement goals that are imposed on individuals.

When taking into account the interpersonal effects of achievement goals, it is doubtful whether goals directed at outperforming others should be encouraged in practice. In light of the current findings, stimulating individuals' mastery goals seems preferable. This recommendation especially holds for social achievement situations-for example, when colleagues or students have to work together-because mastery goals may create team viability (Sundstrom et al. 1990). These kinds of situations are not hypothetical. As the example in the introduction suggest, achievement situations in which only one employee or student is rewarded or promoted are very common in academic and organizational life. More strongly, in economics promotion decisions have been conceptualized as tournament in which the "winner" gets the desired position (Chen 2003). Self-evidently, in such situations, individuals may easily start to compete with each other, which can lead to unwanted effects such as sharing inaccurate information or even sabotaging other's work (e.g., Maher 2010). In the long run, setting performance goals may, therefore, not only be considered potentially harmful for interpersonal relations, but also for organizations as a whole.

However, given the inherently competitive nature of, for example, sports and business contexts, suppression of performance goals is not always warranted. Obviously, performing better than others is in some of those contexts formally agreed upon and by no means unethical (e.g., outperforming a business competitor, winning a basketball game). However, the current series of studies has demonstrated that behaviors stemming from performance goals may also sabotage the task efforts of others, even in contexts in which exchange partners are dependent on each other. Although performance goals may deter the potentially positive dynamics of such interdependent processes, when competitive behavioral tendencies are channeled toward outgroup competitors this can obviously enhance the success of the own group. So, to offer the simple and generic suggestion that performance goals should be discouraged may be unrealistic. Rather, it would be more advisable to promote mastery goals. However, it is uncertain which contextual elements of achievement situations should be altered in order to make mastery goals more salient. Ideally, solutions should be tailored to fit the specific task context in order to harvest the potentially positive effects of mastery goals. Granted, creating climates that exclusively focus on mastery goals may be practically in conflict with organizational and academic realities (cf. Bunderson and Sutcliffe 2003; DeShon and Gillespie 2005).

However, recent research has indicated that social norms in the achievement context are an important source of the individual goal setting process. Thus, one promising way to encourage particular goals is by setting specific norms (Darnon et al. 2009; see also Ordóñez et al. 2009). Also, there is no question that goal setting is a powerful and widely applicable technique to attain desirable task outcomes (Latham and Locke 2006; Locke and Latham 2002). Consequently, we are quite hopeful that individuals are able to actually set mastery goals in interdependent situations rather than performance goals. Ironically, the high level of task performance that one was hoping to achieve by stimulating performance goals may actually result in lowered group performance due to collateral interpersonally harmful behavior. From that perspective, setting mastery goals might as well be perceived as lowhanging fruit that is a quite uncomplicated avenue to smoothen interpersonal processes in social achievement situations.

This study has a couple of limitations that need to be addressed. First, with regard to the experimental designs of Study 1 and 2, it should be noted that no control condition was included in which no goal was assigned. Of course, such a baseline condition would provide additional insight 
into the specific goal that drives the observed effects in the study. Earlier work showed that a mastery goal condition resulted in comparable benevolent information exchange behavior compared to a no-goal condition (Poortvliet et al. 2007). However, in that particular study a difference was found between the mastery goal condition and the no-goal condition with regard to the underlying psychological mechanisms. Specifically, mediation analyses revealed that the effect of the performance goal condition on the information giving measure was mediated by reciprocity orientation and exploitation orientation, but only relative to the mastery goal condition, and not relative to the no-goal control condition. Apparently, in such exchange situations, people typically follow the norm of reciprocity. A performance goal motivates individuals to breach the reciprocity norm, whereas a mastery goal reinforces this norm.

Second, we only looked at exchange processes at the dyadic level and we investigated these processes in a controlled lab setting. Naturally, the interpersonal effects of achievement goals could be different if the two parties shared a common identity, purpose, incentive, or long-term relationship. Also, these effects would probably be different when individuals compete with a common adversary. Indeed, Carnevale and Probst (1997) argue that especially competitive people who strive against an outgroup have the propensity to be both more flexible and more constructive in reaction to properties of the social context. It could, therefore, very well be that performance driven individuals would be equally likely, or even more likely to want to cooperate with an exchange partner from their ingroup, relative to mastery individuals, so long as they are focused on earning both a team and an individual incentive.

Furthermore, in the present research the effects on interpersonally behavior of imposed achievement goals were studied. However, research has indicated that achievement goals may operate at motivational levels beyond just situational ones. In their classical works, Nicholls (1984) and Dweck (1986) established that individuals differ in the way in which they are oriented toward distinct achievement goals. As such, achievement goals may reflect rather stable personality characteristics. However, there is also considerable evidence to suggest that features of the situation or the achievement climate may trigger different achievement goals. Thus, achievement goals may act as temporal and situation-specific drives, and individuals may also endorse different levels of achievement goals over time (Button et al. 1996; DeShon and Gillespie 2005; Elliot and McGregor 2001; Payne et al. 2007; Yeo et al. 2009). Interestingly, recent research has demonstrated that persons who have a dominant performance goal, relative to a dominant mastery goal, are more likely to make competitive decisions and less likely to make cooperative decisions (Poortvliet and Giebels, 2011).
It would be interesting for future research to investigate how dispositional or dominant achievement goals, relative to situational or context-specific achievement goals, have effects on deceptive behaviors. Also, it could also be explored whether achievement goals on the dispositional and situational levels might interact with each other with regard to such interpersonally harmful outcomes (cf. DeShon et al. 2004; Yeo et al. 2009).

Another promising avenue would be to simultaneously encourage balanced levels of both performance goals and mastery goals in socially defined task contexts (Barron and Harackiewicz 2001). A multiple goal perspective such as this might combine the best outcome patterns of both achievement goals. The current research shows that, compared to mastery goals, performance goals may lead to destructive interpersonal behaviors. However, other research has indicated that when people exclusively focus on self-improvement and overemphasize task mastery, this may compromise their task performance (Bunderson and Sutcliffe 2003). Furthermore, recently, a different line of research has suggested that mastery goals may be more effective for actual task performance when people receive normative feedback rather than self-referenced feedback (Chen and Mathieu 2008). Earlier research has also argued (Farr et al. 1993) and demonstrated (Janssen and Van Yperen 2004) that the negative or maladaptive effects of performance goals are most salient when mastery goals are absent or relatively weak. These observations suggest that it would be more precise and nuanced to call for the promotion of mastery goals and not the discouragement of performance goals per se. The current study aimed to provide a first step toward a better understanding of the interpersonally harmful effects of achievement goals, and we sincerely hope that future work will incorporate a multiple goal perspective to further the understanding of the important social consequences of achievement motivation.

\section{Conclusion}

In recent years, the achievement goal approach has become one of the dominant frameworks explaining achievement outcomes in organizations, sports, and educational settings. With the aim of identifying which achievement goal should best be promoted in achievement situations, the effects of performance versus mastery goals on various criteria have been examined. The current study extends this line of research by taking a closer look at achievement goal effects on interpersonally harmful behavior in social situations. We showed that performance goals lead to more deceptive information exchange and thwarting behavior relative to mastery goals, especially when the interaction partner is 
believed to have a low task-related competence. These results should caution researchers and policy makers about strengthening performance goals in achievement situations where task performance is highly dependent on social coordination and collaboration.

Acknowledgments The authors would like to thank Jane Debode, Phoebe Mui, and Jana Raver for offering valuable suggestions.

Open Access This article is distributed under the terms of the Creative Commons Attribution Noncommercial License which permits any noncommercial use, distribution, and reproduction in any medium, provided the original author(s) and source are credited.

\section{References}

Abelson, R. P., \& Prentice, D. A. (1997). Contrast tests of interaction hypotheses. Psychological Methods, 2, 315-328.

Anderman, E. M., \& Midgley, C. (2004). Changes in self-reported academic cheating across the transition from middle school to high school. Contemporary Educational Psychology, 29, 499-517.

Anderson, M. S., Ronning, E. A., De Vries, R., \& Martinson, B. C. (2007). The perverse effects of competition on scientists' work and relationships. Science and Engineering Ethics, 13, 437-461.

Barron, K. E., \& Harackiewicz, J. M. (2001). Achievement goals and optimal motivation: Testing multiple goal models. Journal of Personality and Social Psychology, 80, 706-722.

Berkowitz, L. (1998). Affective aggression: The role of stress, pain, and negative affect. In R. G. Geen \& E. Donnerstein (Eds.), Human aggression: Theories, research, and implications for social policy (pp. 49-72). San Diego, CA: Academic Press.

Bunderson, J. S., \& Sutcliffe, K. M. (2003). Management team learning orientation and business unit performance. Journal of Applied Psychology, 88, 552-560.

Bushman, B. J., \& Baumeister, R. F. (1998). Threatened egotism, narcissism, self-esteem, and direct and displaced aggression: Does self-love or self-hate lead to violence? Journal of Personality and Social Psychology, 75, 219-229.

Button, S. B., Mathieu, J. E., \& Zajac, D. M. (1996). Goal orientation in organizational research: A conceptual and empirical foundation. Organizational Behavior and Human Decision Processes, 67, 26-48.

Carnevale, P. J., \& Probst, T. (1997). Good news about competitive people. In C. K. W. De Dreu \& E. Van de Vliert (Eds.), Using conflict in organizations (pp. 129-146). London, UK): Sage.

Chen, K.-P. (2003). Sabotage in promotion tournaments. Journal of Law, Economics and Organization, 19, 119-140.

Chen, G., \& Mathieu, J. E. (2008). Goal orientation dispositions and performance trajectories: The roles of supplementary and complementary situational inducements. Organizational Behavior and Human Decision Processes, 106, 21-38.

Darnon, C., Butera, F., \& Harackiewicz, J. M. (2007). Achievement goals in social interactions: Learning with mastery vs. performance goals. Motivation and Emotion, 31, 61-70.

Darnon, C., Dompnier, B., Delmas, F., Pulfrey, C., \& Butera, F. (2009). Achievement goal promotion at university: Social desirability and social utility of mastery and performance goals. Journal of Personality and Social Psychology, 96, 119-134.

Darnon, C., Dompnier, B., Gilliéron, O., \& Butera, F. (2010). The interplay of mastery and performance goals in social comparison: A multiple-goal perspective. Journal of Educational Psychology, 102, 212-222.

Darnon, C., Muller, D., Schrager, S. M., Pannuzzo, N., \& Butera, F. (2006). Mastery and performance goals predict epistemic and relational conflict regulation. Journal of Educational Psychology, 98, 766-776.

Deci, E., \& Ryan, R. M. (1985). Intrinsic motivation and selfdetermination in human behavior. New York, NY: Plenum.

DeShon, R. P., \& Gillespie, J. Z. (2005). A motivated action theory account of goal orientation. Journal of Applied Psychology, 90, 1096-1127.

DeShon, R. P., Kozlowski, S. W. J., Schmidt, A. M., Milner, K. R., \& Wiechmann, D. (2004). A multiple-goal, multilevel model of feedback effects on the regulation of individual and team performance. Journal of Applied Psychology, 89, $1035-1056$.

Deutsch, M. (1949). A theory of co-operation and competition. Human Relations, 2, 129-152.

Dweck, C. S. (1986). Motivational processes affecting learning. American Psychologist, 41, 1040-1048.

Einarsen, S., Hoel, H. \& Notelaers, G. (2009). Measuring exposure to bullying and harassment at work: Validity, factor structure and psychometric properties of the negative acts questionnairerevised. Work and Stress, 23, 24-44.

Elliot, A. J. (2005). A conceptual history of the achievement goal construct. In A. J. Elliot \& C. S. Dweck (Eds.), Handbook of competence and motivation (pp. 52-72). New York, NY: The Guilford Press.

Elliot, A. J., \& Church, M. A. (1997). A hierarchical model of approach and avoidance motivation. Journal of Personality and Social Psychology, 72, 218-232.

Elliot, A. J., \& McGregor, H. A. (2001). A $2 \times 2$ achievement goal framework. Journal of Personality and Social Psychology, 80, 501-519.

Farr, J. L., Hofmann, D. A., \& Ringenbach, K. L. (1993). Goal orientation and action control theory: Implications for industrial and organizational psychology. International Review of Industrial and Organizational Psychology, 8, 193-232.

Harackiewicz, J. M., Barron, K. E., Carter, S. M., Lehto, A. T., \& Elliot, A. J. (1997). Predictors and consequences of achievement goals in the college classroom: Maintaining interest and making the grade. Journal of Personality and Social Psychology, 73, 1284-1295.

Harackiewicz, J. M., Barron, K. E., Pintrich, P. R., Elliot, A. J., \& Thrash, T. M. (2002). Revision of achievement goal theory: Necessary and illuminating. Journal of Educational Psychology, 94, 638-645.

Harackiewicz, J. M., \& Sansone, C. (1991). Goals and intrinsic motivation: You can get there from here. In M. L. Maehr \& P. R. Pintrich (Eds.), Advances in motivation and achievement (vol. 7, pp. 21-49). Greenwich, CT: JAI Press.

Janssen, O., \& Van Yperen, N. W. (2004). Employees' goal orientations, the quality of leader-member exchange, and the outcomes of job performance and job satisfaction. Academy of Management Journal, 47, 368-384.

Johnson, D. W., \& Johnson, R. T. (1989). Cooperation and Competition: Theory and research. Edina, MN: Interactive Book Company.

Johnson, D. W., \& Johnson, F. P. (2009). Joining together: Group theory and group skills (10th edn.). Upper Saddle River, NJ: Pearson.

Jones, E. E. (1990). Interpersonal perception. New York, NY: Freeman.

Kahneman, D., Krueger, A. B., Schkade, D., Schwarz, N., \& Stone, A. A. (2006). Would you be happier if you were richer? A focusing illusion. Science, 312, 1908-1910. 
Kaplan, A., \& Maehr, M. L. (1999). Achievement goals and student well-being. Contemporary Educational Psychology, 24, 330-358.

Kennedy, D. (1997). Academic duty. Cambridge, MA: Harvard University Press.

Kray, L. J., \& Haselhuhn, M. P. (2007). Implicit negotiation beliefs and performance: Experimental and longitudinal evidence. Journal of Personality and Social Psychology, 93, 49-64.

Langer, E. J. (1975). The illusion of control. Journal of Personality and Social Psychology, 32, 311-328.

Latham, G. P., \& Locke, E. A. (2006). Enhancing the benefits and overcoming the pitfalls of goal setting. Organizational Dynamics, 35, 332-340.

Lax, D., \& Sebenius, J. (1986). The manager as negotiator: Bargaining for cooperation and competitive gain. New York, NY: Free Press.

Locke, E. A., \& Latham, G. P. (1990). A theory of goal setting and task performance. Englewood Cliffs, NJ: Prentice Hall.

Locke, E. A., \& Latham, G. P. (2002). Building a practically useful theory of goal setting and task motivation. American Psychologist, 57, 705-717.

Maher, B. (2010). Sabotage!. Nature, 467, 516-518.

Midgley, C., Kaplan, A., \& Middleton, M. (2001). Performanceapproach goals: Good for what, for whom, under what circumstances, and at what cost? Journal of Educational Psychology, 93, 77-86.

Murdock, T. B., \& Anderman, E. M. (2006). Motivational perspectives on student cheating: Toward an integrated model of academic dishonesty. Educational Psychologist, 41, 129-145.

Nicholls, J. G. (1984). Achievement motivation: Conceptions of ability, subjective experience, task choice, and performance. Psychological Review, 91, 328-346.

Ordóñez, L. D., Schweitzer, M. E., Galinsky, A. D., \& Bazerman, M. H. (2009). On good scholarship, goal setting, and scholars gone wild. Academy of Management Perspectives, 23, 82-87.

Payne, S. C., Youngcourt, S. S., \& Beaubien, J. M. (2007). A metaanalytic examination of the goal orientation nomological net. Journal of Applied Psychology, 92, 128-150.

Poortvliet, P. M., \& Darnon, C. (2010). Toward a more social understanding of achievement goals: The interpersonal effects of mastery and performance goals. Current Directions in Psychological Science, 19, 324-328.

Poortvliet, P. M. \& Giebels, E. (2011). Self-improvement and cooperation: How exchange relationships promote masteryapproach driven individuals' job outcomes. European Journal of Work and Organizational Psychology. doi:10.1080/1359432X. 2011.555080.

Poortvliet, P. M., Janssen, O., Van Yperen, N. W., \& Van de Vliert, E. (2007). Achievement goals and interpersonal behavior: How mastery and performance goals shape information exchange. Personality and Social Psychology Bulletin, 33, 1435-1447.

Poortvliet, P. M., Janssen, O., Van Yperen, N. W., \& Van de Vliert, E. (2009a). Low ranks make the difference: How achievement goals and ranking information affect cooperation intentions. Journal of Experimental Social Psychology, 45, 1144-1147.

Poortvliet, P. M., Janssen, O., Van Yperen, N. W., \& Van de Vliert, E. (2009b). The joint impact of achievement goals and performance feedback on information giving. Basic and Applied Social Psychology, 31, 197-209.

Porter, C. O. L. H. (2005). Goal orientation: Effects on backing up behavior, performance, efficacy, and commitment in teams. Journal of Applied Psychology, 90, 811-818.

Rosenthal, R., Rosnow, R. L., \& Rubin, D. (2000). Contrasts and effect sizes in behavioral research: A correlational approach. Cambridge, UK: Cambridge University Press.
Schweitzer, M. E., Ordóñez, L., \& Douma, B. (2004). Goal setting as a motivator of unethical behavior. Academy of Management Journal, 47, 422-432.

Sigall, H., \& Mills, J. (1998). Measures of independent variables and mediators are useful in social psychology experiments: But are they necessary? Personality and Social Psychology Review, 2, 218-226.

Skaalvik, E. M. (1997). Self-enhancing and self-defeating ego orientation: Relations with task and avoidance orientation, achievement, self-perceptions, and anxiety. Journal of Educational Psychology, 89, 71-81.

Spencer, S. J., Zanna, M. P., \& Fong, G. T. (2005). Establishing a causal chain: Why experiments are often more effective than mediational analyses in examining psychological processes. Journal of Personality and Social Psychology, 89, 845-851.

Sundstrom, E., De Meuse, K. P. \& Futrell, D. (1990). Work teams: Applications and effectiveness. American Psychologist, 45, 120-133.

Toma, C., \& Butera, F. (2009). Hidden profiles and concealed information: Strategic information sharing and use in group decision making. Personality and Social Psychology Bulletin, 35, 793-806.

Van de Vliert, E. (1997). Complex interpersonal conflict behaviour: Theoretical frontiers. Hove, UK: Psychology Press.

Van de Vliert, E. (1998). Conflict and conflict management. In P. J. D. Drenth, H. Thierry, \& C. J. De Wolff (Eds.), Handbook of work and organizational psychology: Personnel psychology (Vol. 3, pp. 351-376). Hove, UK: Psychology Press.

Van de Vliert, E., \& Janssen, O. (2002). 'Better than' performance motives as roots of satisfaction across more and less developed countries. Journal of Cross Cultural Psychology, 33, 380-397.

Van Yperen, N. W. (2003). Task interest and actual performance: The moderating effects of assigned and adopted purpose goals. Journal of Personality and Social Psychology, 85, 1006-1015.

Van Yperen, N. W. (2006). A novel approach to assessing achievement goals in the context of the $2 \times 2$ framework: Identifying distinct profiles of individuals with different dominant achievement goals. Personality and Social Psychology Bulletin, 32, $1432-1445$.

Van Yperen, N. W., Hamstra, M. R. W., \& Van der Klauw, M. (2011). To win, or not to lose, at any cost: The impact of achievement goals on cheating. British Journal of Management, 22, S5-S15.

Van Yperen, N. W., \& Janssen, O. (2002). Fatigued and dissatisfied or fatigued but satisfied? Goal orientations and responses to high job demands. Academy of Management Journal, 45, 1161-1171.

Vardi, Y., \& Weitz, E. (2004). Misbehavior in organizations: Theory, research, and management. Mahway, NJ: Lawrence Erlbaum.

Vilanova, P., \& Bernardin, H. J. (1989). Impression management in the context of performance appraisal. In R. A. Giacalone \& P. Rozenfeld (Eds.), Impression management in the organization (pp. 299-313). Hillsdale, NJ: Lawrence Erlbaum.

Wathne, K. H., \& Heide, J. B. (2000). Opportunism in interfirm relationships: Forms, outcomes, and solutions. Journal of Marketing, 64, 35-51.

Wong, A., Tjosvold, D., \& Yu, Z. (2005). Organizational partnerships in China: Self-interest, goal interdependence, and opportunism. Journal of Applied Psychology, 90, 782-791.

Yeo, G., Loft, S., Xiao, T., \& Kiewitz, C. (2009). Goal orientations and performance: Differential relationships across levels of analysis and as a function of task demands. Journal of Applied Psychology, 94, 710-726. 